D.O.I.: $10.3895 / \mathrm{S} 1808-04482008000400007$

\title{
INDICADORES DE INOVAÇÃO TECNOLÓGICA DO PARANÁ E BRASIL EM TERMOS COMPARATIVOS PINTEC
}

\section{INDICATORS OF TECHNOLOGICAL INNOVATION IN BRAZIL AND PARANÁ IN TERMS PINTEC COMPARATIVE}

\author{
Fabio Fernando Kobs ${ }^{1}$; Dálcio Roberto dos Reis ${ }^{2}$; Hélio Gomes de Carvalho ${ }^{3}$ \\ ${ }^{1}$ Universidade Tecnológica Federal do Paraná - UTFPR - Curitiba - Brasil fabio@creativenet.com.br \\ ${ }^{2}$ Universidade Tecnológica Federal do Paraná - UTFPR - Curitiba - Brasil dalcioreis@terra.com.br \\ ${ }^{3}$ Universidade Tecnológica Federal do Paraná - UTFPR - Curitiba - Brasil heliogcarvalho@terra.com.br
}

\begin{abstract}
Resumo
Este documento apresenta os principais indicadores do Estado do Paraná, comparados com o desempenho do Brasil na Pesquisa de Inovação Tecnológica, sobre as atividades inovativas realizadas pelas empresas industriais entre os anos de 2003 e 2005. O objetivo principal deste estudo é levantar e apresentar os principais indicadores presentes na Pesquisa de Inovação Tecnológica 2005 em termos Paraná e Brasil. A classificação deste artigo, no ponto de vista de seus objetivos, classifica-se como pesquisa exploratória e, quanto aos procedimentos, classifica-se como pesquisa bibliográfica e documental. O método de pesquisa utilizado do ponto de vista da forma de abordagem do problema é de pesquisa quantitativa. Os indicadores encontrados apontam que o PR possui um número superior de empresas que implementaram inovações, o que pode ainda ser superior se elevar o grau de importância à $P \& D$, melhor a qualificação do pessoal, o que garantirá maior apoio do governo em programas de incentivo à inovação. Nesse contexto, as políticas de apoio surgem como instrumento relevante para apoiar as indústrias no Brasil.
\end{abstract}

Palavras-chave: inovação organizacional; inovação tecnológica; pintec.

\section{Introdução}

Este artigo apresenta como principal problema o desconhecimento dos indicadores de inovação das indústrias do Estado do Paraná (PR) e do Brasil.

O objetivo principal deste estudo é levantar e apresentar os principais indicadores presentes na Pesquisa de Inovação Tecnológica 2005 (PINTEC, 2005) em termos PR e Brasil, sobre as atividades inovativas realizadas pelas empresas industriais entre os anos de 2003 e 2005.

Através deste estudo, segundo a PINTEC (2005), os indicadores da pesquisa poderão ser usados pelas empresas para análise de mercado, pelas associações de classe para estudos sobre desempenho e outras características dos setores investigados, e pelo governo para desenvolver e 
avaliar políticas nacionais e regionais, por permitir conhecer e acompanhar a evolução destes indicadores no tempo.

Os objetivos específicos são: conhecer e apresentar os indicadores de inovação do Estado do PR; conhecer e apresentar os indicadores de inovação no Brasil; analisar o desempenho do PR em termos Brasil.

As informações apresentadas no presente artigo para o PR e Brasil referem-se: resultados do processo inovativo; sobre o esforço empreendido para inovar; identificação do impacto das inovações no desempenho das empresas; fontes de informação e relações de cooperação estabelecidas com outras organizações; apoio do governo para as atividades inovativas; e identificação dos problemas e obstáculos para a implementação de inovação.

Este artigo está estruturado da seguinte forma: breve apresentação da PINTEC (2005); conceituação de inovação organizacional e tecnológica; procedimentos metodológicos; resultados; considerações finais; e referências.

\section{PINTEC 2005}

A Pesquisa Industrial de Inovação Tecnológica, realizada pelo IBGE com o apoio da Financiadora de Estudos e Projetos - FINEP e do Ministério da Ciência e Tecnologia, tem por finalidade a construção de indicadores nacionais e regionais das atividades de inovação tecnológica desenvolvidas nas empresas industriais brasileiras com 10 ou mais pessoas ocupadas.

Sendo o processo tecnológico um componente crucial para o desenvolvimento econômico, as informações que permitam entender seu processo de geração, difusão e incorporação pelo aparelho produtivo são de fundamental importância para o desenho, implementação e avaliação de políticas voltadas para a sua promoção e na definição das estratégias privadas. Neste sentido, as informações da PINTEC, ao possibilitarem a construção de indicadores abrangentes, e com comparabilidade internacional, contribuem para ampliar o entendimento do processo de inovação tecnológica nas empresas brasileiras. A primeira pesquisa foi realizada no ano 2000.

A construção de indicadores sobre o processo de inovação tecnológica, alinhados a padrões metodológicos internacionais, contribui para ampliar o entendimento do processo de desenvolvimento industrial e garante sua comparabilidade com dados de outros países.

\section{Inovação Organizacional e Inovação Tecnológica}

Inovação é a introdução de novidade ou aperfeiçoamento no ambiente produtivo ou social que resulte em novos produtos, processos ou serviços (Lei Federal n. ${ }^{\circ}$ 10.973/2004). 
Segundo Reis (2003) inovação tecnológica é a introdução no mercado, com êxito, de novos produtos ou tecnologias no processo de produção ou nas próprias organizações.

O principal agente de mudança no mundo atual é a inovação tecnológica. O progresso econômico e social de diversos países e o êxito das empresas, principalmente industriais, depende da eficiência e da eficácia com que o conhecimento técnico-científico é produzido, transferido, difundido e incorporado aos produtos e serviços, segundo Sbragia et al. (1996).

A inovação à qual se refere Schumpeter (1911 apud Cavalcante, 1998) contempla aspectos diferenciados - novos produtos e processos, diferenciação de produtos, novos mercados, novas posições de mercado, linhas de fornecimento e distribuição e estruturas de mercado.

A tipologia proposta pelo próprio Schumpeter contempla cinco casos que considerava como inovação:

a) Introdução de um novo bem, isto é, que os consumidores não conheçam, ou de uma qualidade nova do bem;

b) Introdução de um novo método de produção, incluindo um novo modo de manusear comercialmente uma mercadoria;

c) Abertura de um novo mercado, onde o ramo da indústria em questão não tenha penetrado;

d) Conquista de uma nova fonte de matéria-prima;

e) Estabelecimento de uma nova organização, uma indústria, tal como criar ou romper uma posição de monopólio.

Drucker (1987) afirma que inovação inicia-se com a cogitação da análise de oportunidades inovadoras, buscando "o elo que falta" em um processo de fabricação. Todas as fontes de oportunidade inovadora devem ser sistematicamente analisadas e sistematicamente estudadas. Uma inovação para ser eficaz precisa ser simples e tem que ser concentrada em fazer somente uma coisa específica e clara, caso contrário, ela confunde e corre o risco de não funcionar. É melhor que as inovações comecem pequenas, exigindo inicialmente poucos recursos, com mercado pequeno e limitado; assim existe tempo suficiente para fazer ajustes e mudanças, caso necessário. Uma inovação bem sucedida visa à liderança desde o início, senão simplesmente irá criar uma oportunidade para a concorrência.

Para Reis e Carvalho (2002), uma organização inovadora é uma criadora de conhecimentos, que valoriza as idéias criadoras dos trabalhadores, bem como seus ideais, e é isso que alimenta a inovação. A abordagem japonesa de gestão da mão-de-obra enfoca o aproveitamento do conhecimento tácito do trabalhador, onde seus "palpites" podem se tornar protótipos de inovações para uso pela empresa. Mas para isso, a empresa precisa dar condições e estímulo ao colaborador, para que se sinta estimulado para criar ainda mais. 
Kelley e Littman (2001) possuem uma metodologia desenvolvida e aprimorada para a inovação, descrita nas cinco etapas básicas a seguir:

- Compreender o mercado, o cliente, a tecnologia e as limitações identificadas do problema;

- Observar pessoas em situações da vida real para descobrir o que modifica o comportamento: o que as confunde, do que gostam, o que detestam, onde têm necessidades latentes não atendidas pelos produtos e serviços atuais;

- Visualizar conceitos novos para o mundo e para os clientes que usarão e, até mesmo simular um vídeo que retrate a vida com o futuro produto antes que ele realmente exista;

- Avaliar e aprimorar os protótipos, ficando atento ao que funciona e ao que não funciona, o que confunde as pessoas, do que parecem gostar, de maneira a desenvolver o produto de modo incremental;

- Implementar o novo conceito para comercialização.

O processo de aprendizagem organizacional e inovação para Fleury e Fleury (1997) ganham novos contornos e dimensões quando trabalhados em diferentes contextos organizacionais, setoriais e nacionais, podendo ser conquistado com a adoção dos seguintes pressupostos: pensar sistematicamente; agir estrategicamente; integrar os processos de decisão e usar inteligentemente a informação; cooperar na competição; definir políticas de recursos humanos que sustentem e impulsionem a aprendizagem e a inovação; e desenvolver uma cultura de aprendizagem.

\section{Procedimentos metodológicos}

A pesquisa classifica-se de acordo com os seus objetivos como pesquisa exploratória, pois para Moreira e Caleffe (2006) tem como principal finalidade desenvolver e esclarecer conceitos e idéias.

No que tange à classificação da pesquisa quanto aos procedimentos usados no presente artigo, é de pesquisa bibliográfica - que para Moreira e Caleffe a pesquisa é desenvolvida a partir de material já elaborado, constituído principalmente de livros e artigos científicos - e pesquisa documental - segundo Moreira e Caleffe a coleta de dados está restrita a documentos realizados em centros de pesquisa, neste artigo, à PINTEC (2005) do IBGE.

Quanto aos métodos de abordagem do problema classifica-se como quantitativa, onde para Moreira e Caleffe (2006) distinguem esse tipo de pesquisa como a que explora as características e situações de que dados numéricos podem ser obtidos, e, faz uso da mensuração e estatísticas.

A construção dos gráficos e tabelas dar-se-á mediante utilização da ferramenta Microsoft Excel $^{\circledR}$. 


\section{Demonstração e Análise dos Resultados}

Para os indicadores a seguir, foram consideradas as indústrias extrativas (madeira, flor, carvão, extração de minerais, entre outras) e as indústrias de transformação.

A PINTEC (2005) traz as evidências estatísticas sobre a inovação tecnológica nos serviços de telecomunicações, informática e pesquisa e desenvolvimento e atualiza as informações levantadas nas PINTECs 2000 e 2003, sobre as atividades inovativas realizadas pelas empresas industriais entre os anos de 2003 e 2005. Vale ressaltar que para o presente estudo, foram considerados os valores totais, não setorizados, e de forma sucinta os principais indicadores.

Um aspecto relevante para a compreensão dos resultados da PINTEC (2005) diz respeito à conjuntura econômica do período analisado. Segundo os dados da nova série do Sistema de Contas Nacionais do IBGE, devido à adoção de políticas físcal e monetária restritivas, o ano de 2003 caracterizou-se por modestas taxas anuais de crescimento da economia $(1,1 \%)$ e da indústria $(1,3 \%)$, pela redução do ritmo de crescimento dos serviços de informação $(4,4 \%)$, e por variações positivas em apenas dois componentes da demanda agregada: o consumo do governo $(1,2 \%)$ e as exportações de bens e serviços (10,4\%).

Em 2005, uma soma de fatores, como taxa básica de juros relativamente mais baixa face à vigente em 2003, inflação declinante, expansão do crédito e permanência de condições externas favoráveis, contribuiu para que a economia brasileira apresentasse um desempenho melhor do que o obtido em 2003. Na comparação com o ano anterior, o Produto Interno Bruto - PIB cresceu 2,9\%, a indústria $2,2 \%$ e os serviços de informação 4,3\%. Pela ótica da demanda, todos os seus componentes registraram crescimento. Na balança de bens e serviços, houve a segunda variação positiva das importações (9,3\%, em 2005, após alcançar 13,3\%, em 2004) e a conservação da trajetória de expansão das exportações em elevados patamares - 10,1\%, em 2005, e 15,3\%, em 2004 - mesmo com a apreciação da taxa de câmbio desde o final de 2004. Outros destaques foram o consumo das famílias, que ampliou 4,7\%, em 2005, contra 3,8\%, em 2004, e a formação bruta de capital fixo, cujos crescimentos de 3,6\%, em 2005, e 9,1\%, em 2004, contribuíram para que o seu peso no PIB mantivesse a trajetória de recuperação de 15,3\%, em 2003, para 16,1\%, em 2004, e $16,3 \%$, em 2005 .

Desta forma, o primeiro indicador refere-se aos resultados do processo inovativo, apresentado na Tabela 1, o qual demonstra que o Brasil obteve a taxa de inovação de 33,4\%, enquanto o PR conseguiu 40,5\%, ou seja, desempenho de 7,1\% superior ao Brasil. Tal comportamento aparece em todos os tipos de inovações, ou seja, de produto, de processo e de produto e processo. Observa-se na Tabela 1, que o PR obteve desempenho inferior, quando 
comparado ao Brasil, nas inovações tanto de produto novo como de processo novo para o mercado nacional.

Tabela 1 - Empresas que implementaram inovações

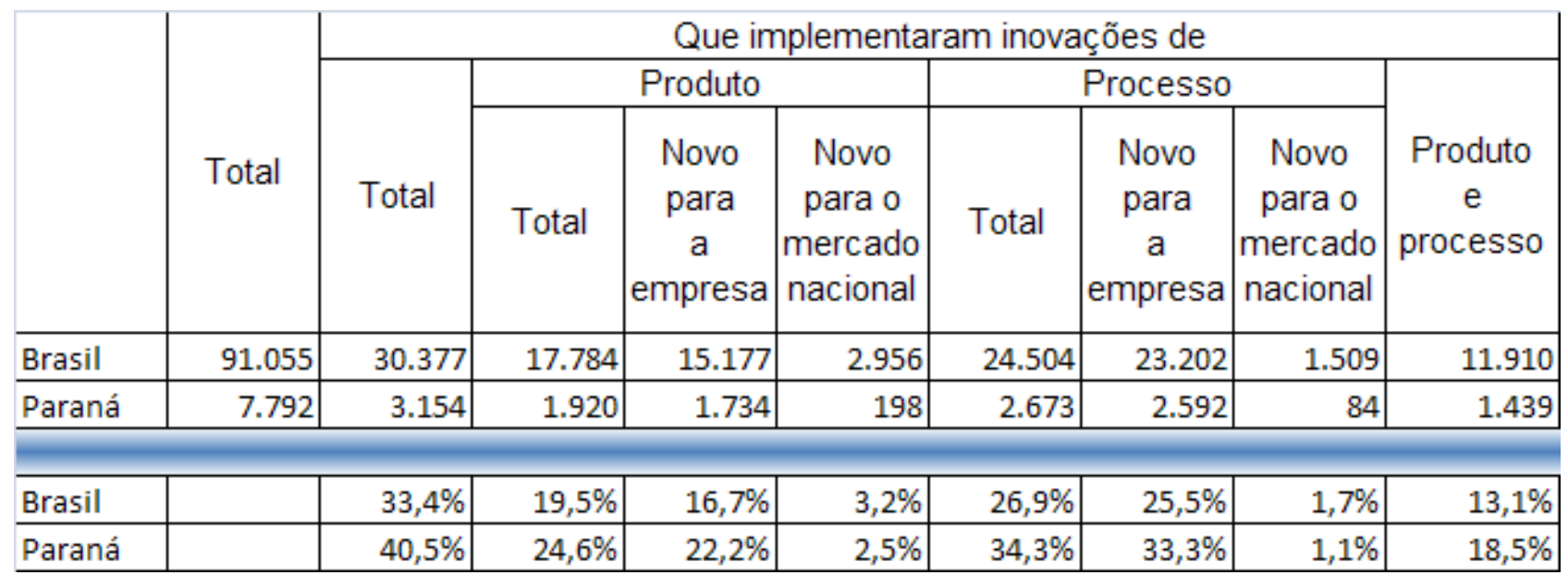

Fonte: IBGE (2005)

Ainda de acordo com a Tabela 1, o universo de empresas com 10 ou mais pessoas ocupadas somava 84,3 mil, em 2003, e passou a abranger cerca de 91 mil empresas, em 2005. Praticamente na mesma proporção, elevou-se o número de empresas que implementaram produto e/ou processo tecnologicamente novo ou substancialmente aprimorado - de 28 mil para 30,4 mil - o que fez a taxa de inovação de 33,4\%, do triênio 2003-2005, manter-se em patamar igual (33,3\%) ao da registrada nos anos de 2001-2003, mas com leve mudança na sua composição. Entre 2001-2003, as empresas industriais adotaram, principalmente, a estratégia de inovar em produto e processo $(14,0 \%)$. Nos anos de 2003-2005, a orientação de inovar só em processo obteve uma leve predominância (13,8\%).

Outro indicador apresenta o esforço empreendido pelas indústrias para inovar, ou seja, a percepção qualitativa da importância das atividades desenvolvidas para inovar, por grau de importância. Mediante o Gráfico 1, observa-se que a mais assinalada na pesquisa foi a atividade de aquisição de máquinas e equipamentos, seguindo de treinamento. Atividades internas de P\&D e aquisição externa de P\&D, se somadas, o PR fica com 16,2\% e o Brasil com 20,6\%, ou seja, desempenho inferior do $\mathrm{PR}$ em 4,4\% nas atividades relacionadas à P\&D. Observa-se também que o desenvolvimento e a absorção de tecnologia mediante a aquisição de máquinas e equipamentos continuam sendo a atividade de maior relevância no esforço inovativo do setor $(65,3 \%$ Brasil e 68,8\% Paraná) e as atividades complementares à compra de bens de capital, como treinamento (44,7\% Brasil e 45,2\% Paraná) e projeto industrial (25,9\% Brasil e 23,3\% Paraná), permanecem na segunda e terceira posições. Com relação à PINTEC 2003, houve um aumento no número de empresas atribuindo importância alta ou média para quase todas as atividades, destacadamente para a aquisição de outros conhecimentos externos. Cabe aqui esclarecer que a PINTEC (2005) 
desmembrou este item em dois, para permitir comparabilidade com as PINTECs passadas e também com as pesquisas dos outros países. Assim, parte do crescimento desta atividade pode estar relacionado ao seu desmembramento e, portanto, ao efeito causado pela maior visibilidade da aquisição de software junto aos informantes.

Gráfico 1 - Grau de importância das atividades inovativas

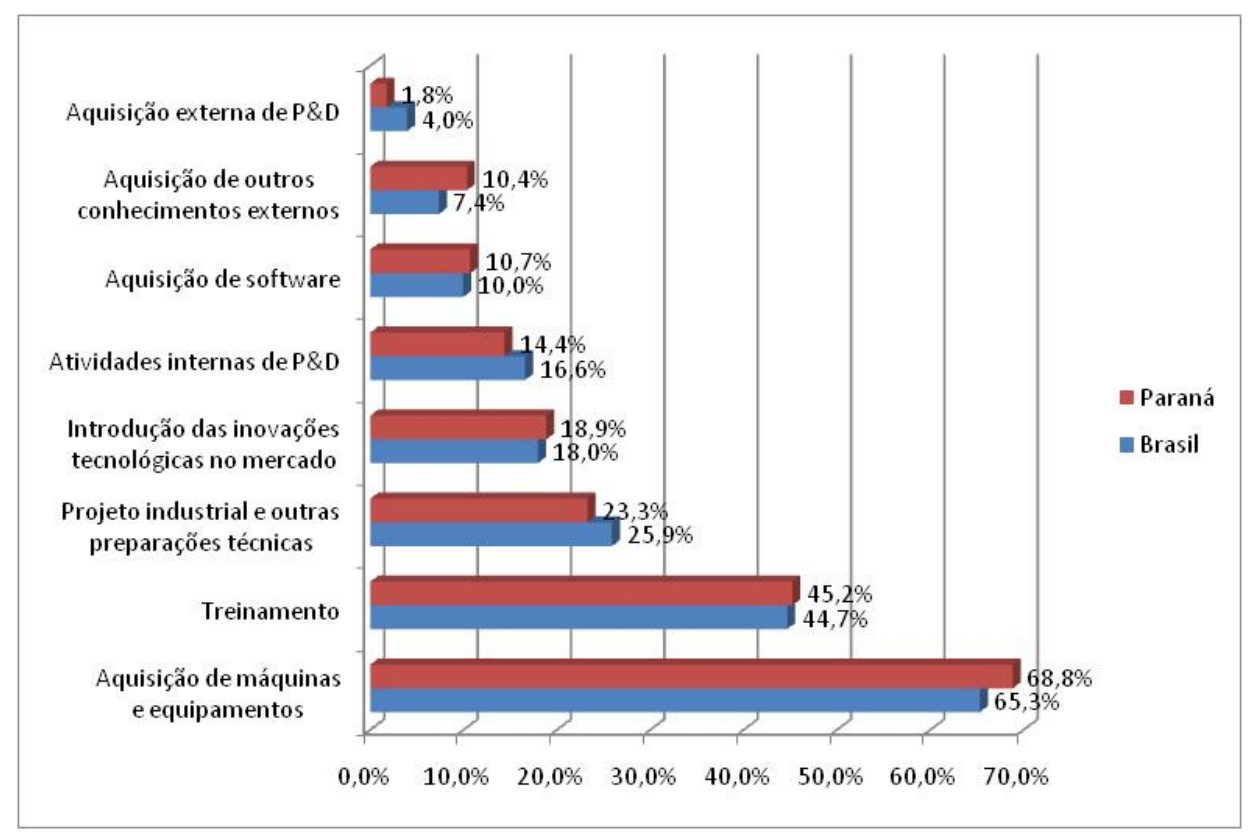

Fonte: IBGE (2005).

As decisões de implementar produtos e processos tecnologicamente novos ou substancialmente aprimorados são motivadas por expectativas de ganhos futuros de competitividade e, posteriormente, de lucro que possam gerar. O Gráfico 2 consolida a freqüência com que os impactos de inovação, foram apontados pelas empresas. Pode-se observar que no Brasil a maioria das empresas cita como impacto das inovações: a melhoria da qualidade dos produtos; o aumento da capacidade produtiva; a manutenção e ampliação da participação da empresa no mercado; entre outros. Já no PR, o único impacto que se sobressai em relação ao Brasil é a redução do impacto ambiental e em aspectos ligados à saúde e segurança em 2,2\%, no entanto, não está entre os cinco com maior freqüência. Na indústria, as mudanças com relação à pesquisa anterior são pequenas, exceto no caso da redução do impacto ambiental/saúde e segurança, que passou da sexta para a sétima posição. Deste modo, a hierarquia de importância das cinco mais elevadas freqüências permaneceu a mesma.

As fontes de informação são consideradas um indicador útil para o entendimento do comportamento inovativo, uma vez que na origem de um projeto de inovação existe uma idéia que pode ser proveniente da própria empresa ou de uma fonte externa. Observa-se no Gráfico 3, que as principais fontes de informação do Brasil e PR são: outras áreas internas; fornecedores; clientes ou 
consumidores; feiras e exposições; concorrentes; e conferências. Já o PR se sobressai em relação ao Brasil em: fornecedores; concorrentes; licenças, patentes e know how.

Gráfico 2 - Impacto das inovações

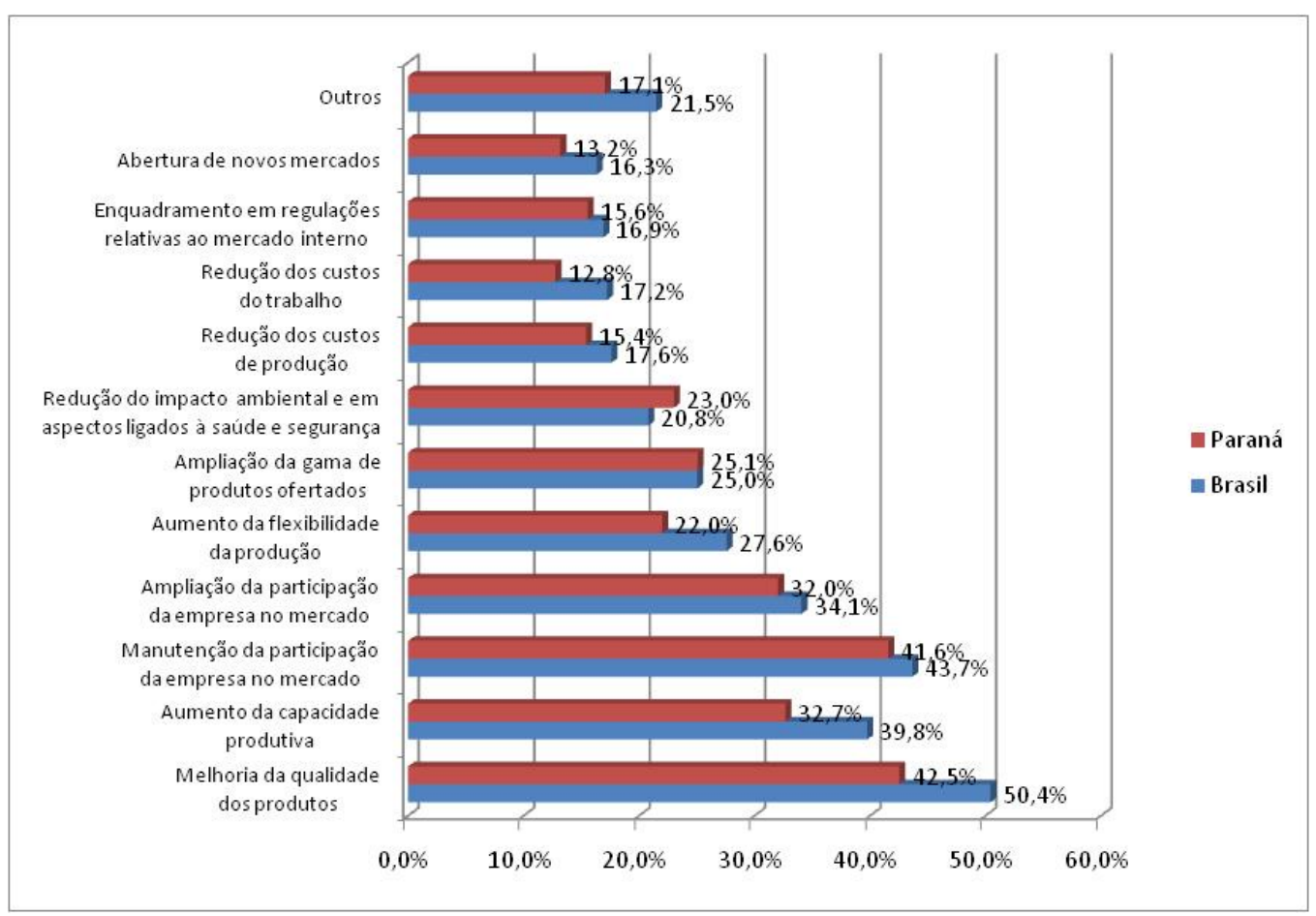

Fonte: IBGE (2005).

Gráfico 3 - Fontes de informação

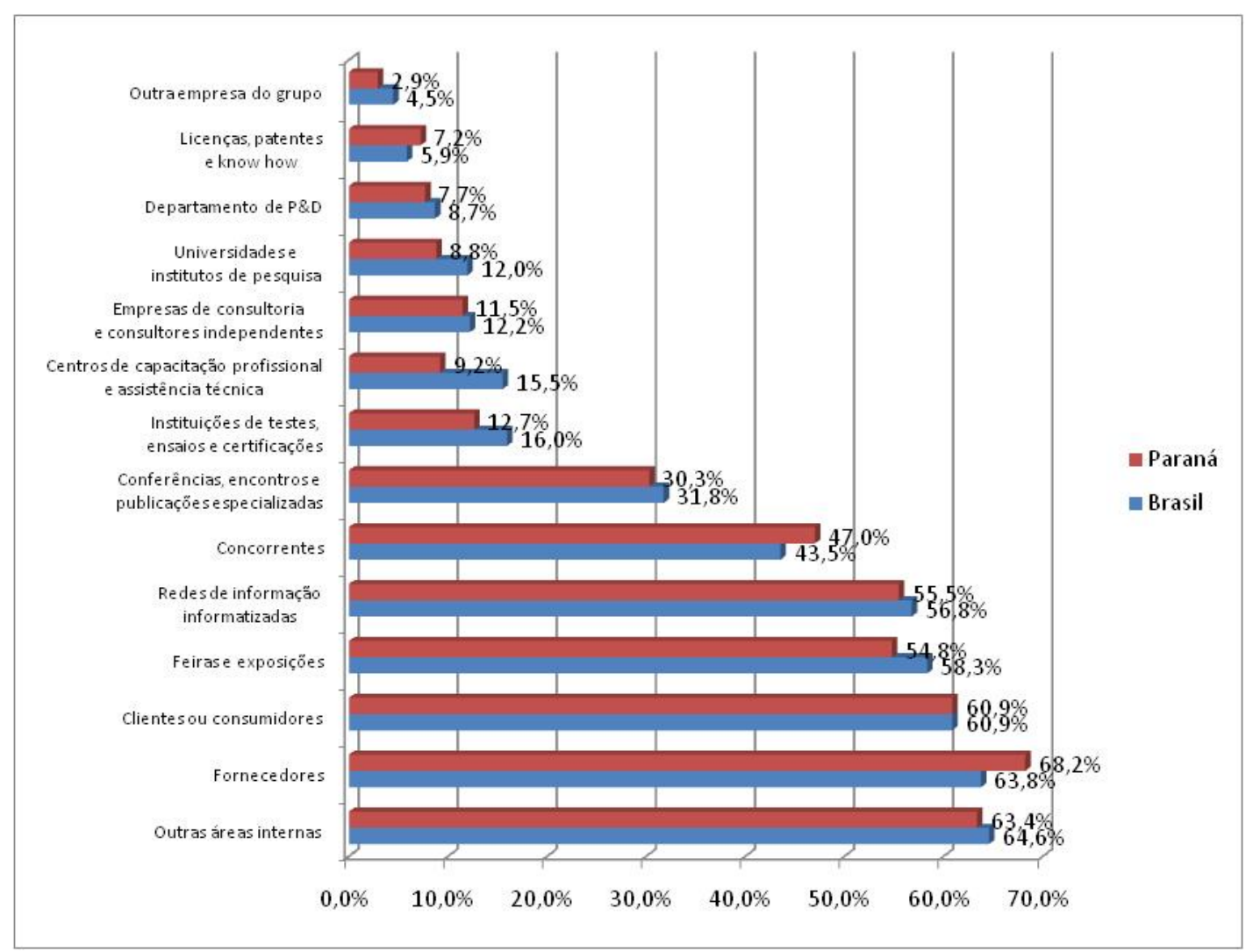

Fonte: IBGE (2005). 
Ainda de acordo com o Gráfico 3, na indústria em relação ao Brasil, um ponto a destacar é que as sete fontes mais importantes repetem as da pesquisa passada, com inversão apenas na terceira e quarta posições. Assim, elas permanecem sendo as áreas internas à empresa (64,6\%), fornecedores $(63,8 \%)$, clientes ou consumidores $(60,9 \%)$ e feiras e exposições $(58,3 \%)$; enquanto aquisições de licenças, patentes e know-how (5,9\%) e outra empresa do grupo (4,5\%) continuam como as fontes menos utilizadas.

As relações de cooperação presentes nas indústrias são apresentadas no Gráfico 4, onde observa-se que, as empresas do PR identificaram relações superiores que o Brasil na grande maioria, exceto nas relações com outra empresa do grupo. Em relação ao conjunto de empresas inovadoras, o percentual, que era de $3,8 \%$, veio para o nível de $7,2 \%$.

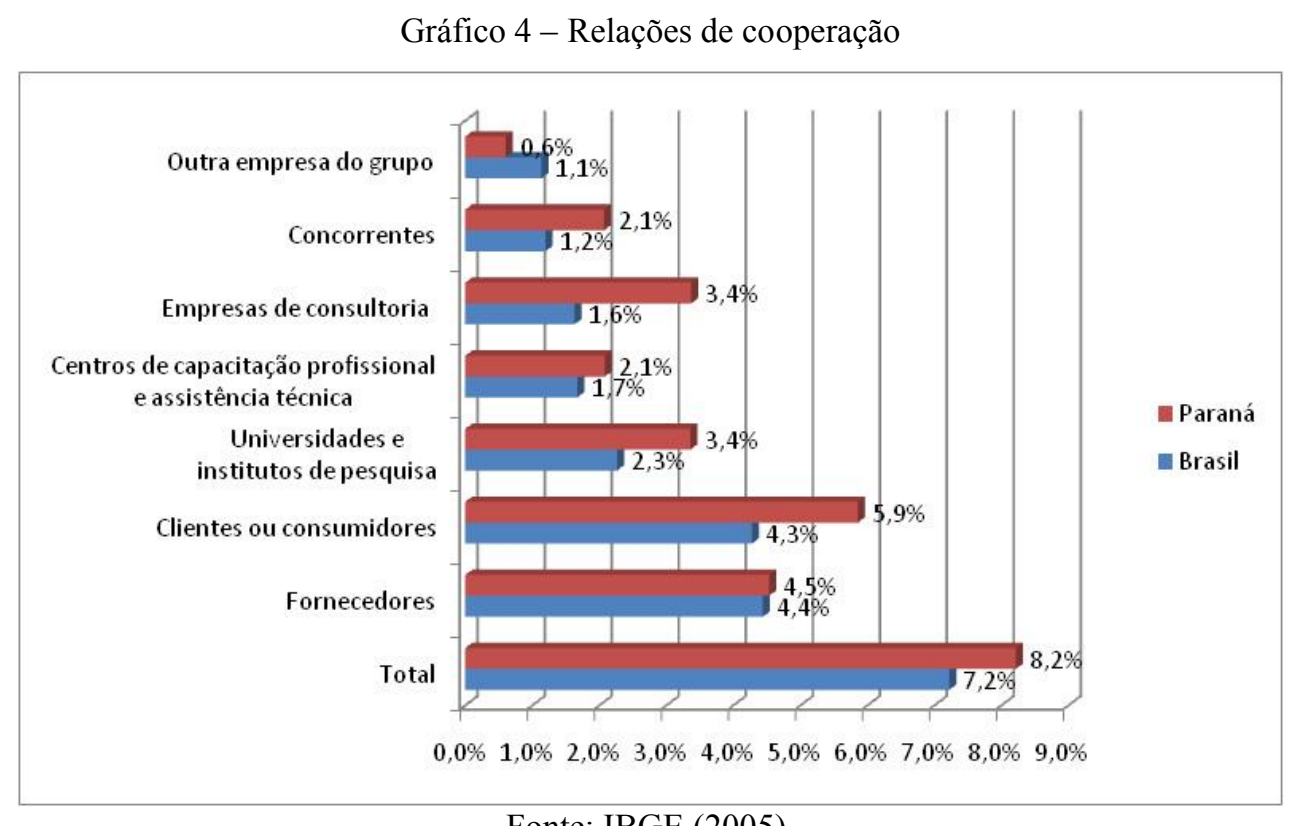

Fonte: IBGE (2005).

As informações relativas aos programas de apoio às atividades inovativas são importantes para a avaliação da adequação e dos impactos produzidos por estes instrumentos de política de incentivo à inovação, as quais podem ser visualizadas na Tabela 2. Em relação ao Brasil, as indústrias do PR receberam apoio menor em todos os tipos de programa, tanto de incentivo fiscal como financiamento. Verifica-se também que na indústria, entre os anos de 2001-2003 e 2003-2005 houve aumento no percentual das empresas que receberam suporte do governo, de 18,7\% para 19,2\%. Na PINTEC (2005), este percentual corresponde a cerca de 5,8 mil no total das 30,4 mil empresas inovadoras. Por faixas de tamanho, verifica-se que esta proporção cresce com o tamanho da empresa: $17,3 \%$ das que empregam entre 10 e 99 pessoas; $24,0 \%$ das que empregam entre 100 e 499 pessoas; e $40,9 \%$ das que empregam 500 ou mais pessoas. 
Tabela 2 - Apoio do governo

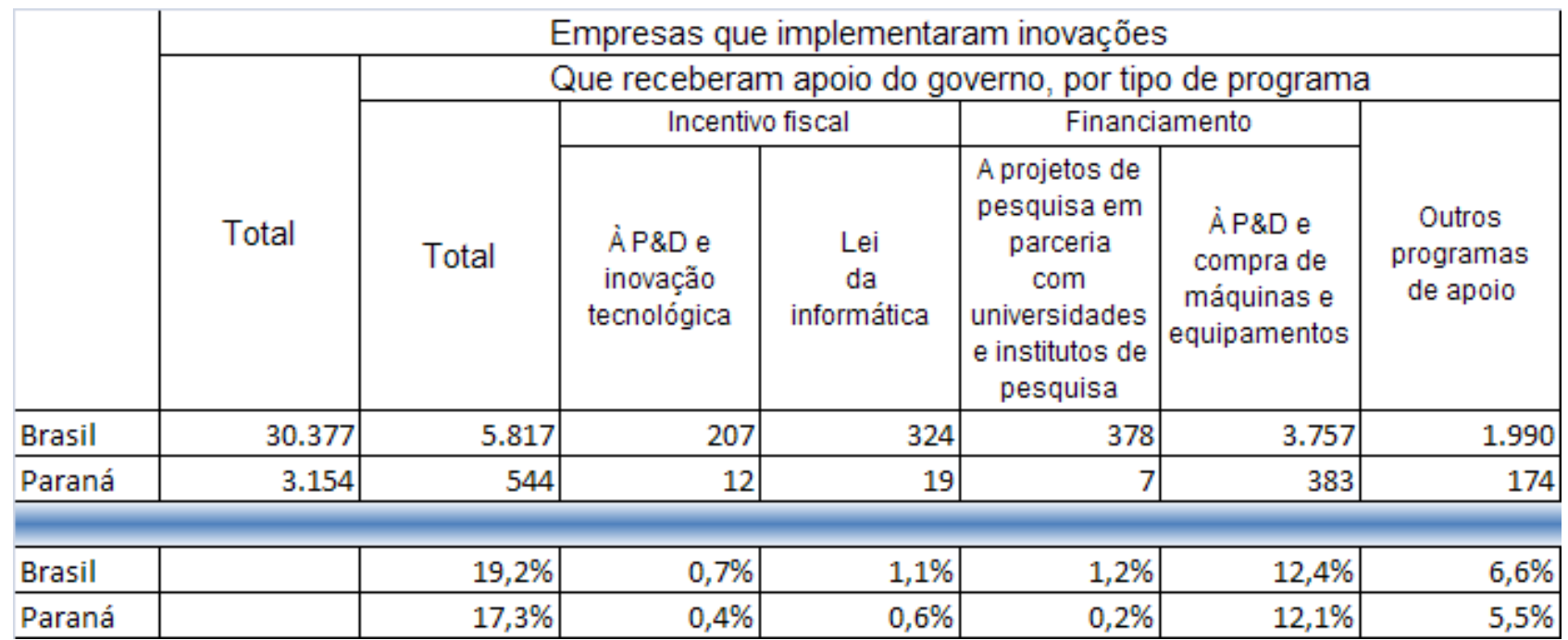

Fonte: IBGE, Diretoria de Pesquisas, Coordenação de Indústria, Pesquisa de Inovação Tecnológica 2005.

De acordo com o PINTEC, na indústria, 34,3\% das 30,4 mil empresas que realizaram inovações no período de 2003-2005 afirmaram terem enfrentado problemas que tornaram mais lento ou inviabilizaram o desenvolvimento de determinados projetos. Considerando que no período de 2001-2003 esse percentual chegou aos 45,4\%, é razoável supor que as condições mais favoráveis do ambiente econômico tenham contribuído para a redução nas dificuldades enfrentadas pelas empresas industriais.

Os motivos pelos quais as empresas não inovam e os obstáculos que encontram no desenvolvimento de suas atividades inovativas constituem informações valiosas para a formulação e avaliação de políticas visando o aumento do desempenho tecnológico e competitivo para as empresas. A ordenação dos principais problemas e obstáculos das empresas que não inovaram, conforme se observa mediante o Gráfico 5, são mais expressivos no PR que no Brasil, são eles: elevados custos da inovação (15,5\% no Brasil e $18,1 \%$ no PR); riscos econômicos excessivos (13,8\% no Brasil e 17,4\% no PR); escassez de fontes apropriadas de financiamento (11,6\% no Brasil e 14,6\% no PR); e falta de pessoal qualificado (5,6\% no Brasil e 6,1\% no PR).

Não representado graficamente devido à simplificação, mas de extrema importância, as razões apontadas pelas indústrias para não inovar, comparando a PINTEC (2005) com os dados da pesquisa anterior, evidencia, em primeiro lugar, que houve leve crescimento na proporção das empresas industriais que não inovaram em produto e/ou processo e não desenvolveram projetos. Em 2003, elas somavam 64,0\% do universo de 84,3 mil empresas. Em 2005, passaram a representar 64,4\% de 91 mil empresas, em razão, basicamente, do aumento de não inovadoras entre as empresas de 10 a 49 pessoas ocupadas. Segundo a PINTEC, evidencia também que se manteve praticamente estável $(11,1 \%$ e $11,3 \%)$ a participação das que justificaram não terem inovado em 
decorrência de terem feito inovações prévias ao período de 2003-2005, e que houve queda (de $23,5 \%$ para $18,6 \%$ ) nas que assinalaram outros fatores impeditivos para inovar. Portanto, as condições de mercado continuaram sendo a principal razão apontada pelas empresas industriais para não terem realizado inovações tecnológicas (de 65,4\% para 70,1\%); houve uma maior concentração de empresas de 10 a 49 pessoas ocupadas declarando este motivo, o que constitui mais um indicador de que empresas de menor porte se beneficiaram relativamente menos que as demais empresas industriais da melhoria no ambiente macroeconômico no período de 2003-2005.

Gráfico 5 - Problemas e obstáculos das empresas que não inovaram

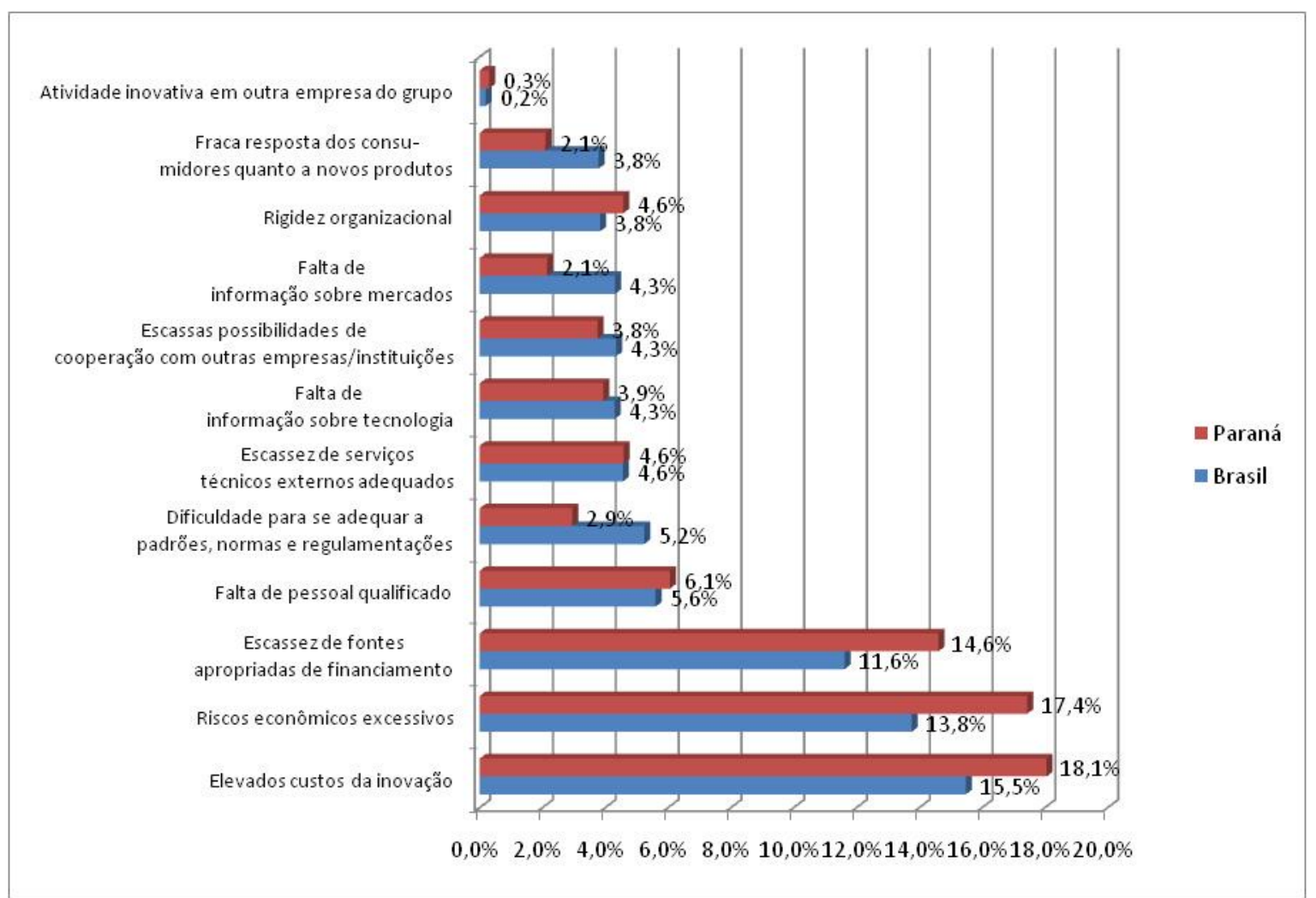

Fonte: IBGE (2005).

\section{Considerações finais}

A demonstração dos resultados e as análises e argumentos utilizados neste artigo permitiram responder, mesmo que parcialmente, o problema formulado no início deste artigo. Nele constava o desconhecimento dos indicadores de inovação das indústrias do PR e do Brasil.

Os resultados da PINTEC (2005) vêm confirmar a influência do ambiente macroeconômico na decisão empresarial de investir em inovação. A coexistência de condições favoráveis provenientes tanto da economia mundial quanto do mercado interno deram suporte para as estratégias inovativas das empresas de serviços, bem como para as tomadas de decisão menos defensivas sobre os investimentos industriais em inovação implementados em 2003. O cenário de 
2005 impulsionou um maior número de empresas industriais a inovar, gastando mais com as atividades inovativas e desenvolvendo mais suas inovações em parceria com outras empresas e institutos, como foi possível observar no presente artigo.

O PR teve desempenho superior, quando comparado ao Brasil, o qual se observou no total de empresas que inovaram. As indústrias no PR devem elevar o grau de importância em relação à $\mathrm{P} \& \mathrm{D}$, bem como ter como fontes de informação equipes de $\mathrm{P} \& \mathrm{D}$, seja interno mediante um departamento ou mesmo com parcerias e cooperação junto a institutos de pesquisa.

Outro item a considerar, o baixo nível de pessoal qualificado, apontado como problema para não implementar inovação, o qual pode refletir em deficientes projetos e, por conseqüência, no impedimento de apoio por parte do governo ao mesmo. Pode ser esta, uma das causas que leva o PR abaixo do Brasil nas empresas que receberam apoio mediante algum tipo de programa de incentivo à inovação.

Assim, cabe ao Brasil orientar, apoiar e estimular o processo de inovação tecnológica, sem desconsiderar que a transformação da indústria é de responsabilidade dela própria. Nesse contexto, as políticas de apoio surgem como instrumento relevante para apoiar as indústrias no Brasil.

\begin{abstract}
This document presents the main indicators of the Parana, compared with the performance of Brazil in search of technological innovation, on the innovative activities carried out by industrial companies between the years 2003 and 2005. The main objective of this study is to raise and present the main indicators in the Search for Technological Innovation 2005 in Parana and Brazil. The classification of this article, in view of their goals, classifies itself as exploratory research, and for procedures, classifies itself as literature search and documentary. The research method used in terms of how to approach the problem is quantitative research. The indicators pointed found that the Parana has a higher number of companies that have implemented innovations, which can still be higher if raising the degree of importance to $\mathrm{R} \& \mathrm{D}$, the better the qualifications of staff, which will ensure greater support from government in programs to encourage innovation. In this context, policies to support emerging as a tool to support the relevant industries in Brazil.
\end{abstract}

Key-words: organizational innovation, technological innovation; pintec.

\title{
Referências
}

BRASIL. Lei de Inovação Tecnológica n. ${ }^{0}$ 10.973/2004. Brasília, DF: Congresso Nacional. Atos do Poder Legislativo, DOU, n. ${ }^{\circ} 232$ de 03.12.2004.

CAVAlCANTE, L. R. M. T. Maturidade tecnológica e intensidade em P\&D: O caso da indústria petroquímica no Brasil. Salvador: FIEB/IEL, 1998.

DRUCKER, P. F. Inovação e espírito empreendedor (entrepreneurship): prática e princípios. Tradução de Carlos Malferrari. 2. ed. São Paulo: Pioneira, 1987.

FLEURY, A. C. C.; FLEURY, M. T. L. Aprendizagem e inovação organizacional: as experiências de Japão, Coréia e Brasil. 2. ed. São Paulo: Atlas, 1997. 
KELley, T.; LiTTMAN, J. A arte da inovação. Tradução de Maria Claudia Lopes. São Paulo: Futura, 2001.

MOREIRA, H.; CALEFFE, L. G. Metodologia da pesquisa para o professor pesquisador. Rio de Janeiro: DP\&A, 2006.

PESQUISA de Inovação Tecnológica - PINTEC 2005. Rio de Janeiro: IBGE, 2007. Disponível em: $<$ http://www.ibge.gov.br/home/estatistica/economia/industria/pintec/2005/pintec2005.pdf >. Acesso em: 14 set. 2007.

REIS, D. R.Gestão da Inovação Tecnológica. São Paulo: Editora Manole, 2003.

REIS, D. R.; CARVALHO, H. G. Gestão tecnológica e inovação. In: BASTOS, J. A. S. A. Capacitação tecnológica e competitividade: o desafio para a empresa brasileira. Curitiba: IEL/PR, 2002. p. 53-75.

SBRAGIA, R.; MARCOVITCH, J. e VASCONCELOS, E. Gestão da Inovação Tecnológica. Anais do XIX Simpósio de Gestão da Inovação Tecnológica. São Paulo: Tec-Art Editora, 1996.

\section{Dados completos dos autores:}

Nome completo: FABIO FERNANDO KOBS

Filiação institucional: Mestrando do programa de pós-graduação em Tecnologia - UTFPR

Departamento: PPGTE

Função ou cargo ocupado: Aluno

Endereço completo para correspondência (bairro, cidade, estado, país e CEP): Centro, Rua Manoel Tavares, 85, Apto. 403, São Bento do Sul, SC, Brasil, 89.290-000

Telefones para contato: $473635-2125 \quad 47$ 9986-0099

e-mail: fabio@creativenet.com.br

Nome completo: DÁLCIO ROBERTO DOS REIS

Filiação institucional: Professor do programa de pós-graduação em Tecnologia - UTFPR

Departamento: PPGTE

Função ou cargo ocupado: Professor.

Endereço completo para correspondência (bairro, cidade, estado, país e CEP): Centro, Av. Sete de Setembro, 3165, Curitiba, PR, Brasil, 80.230-901

Telefones para contato: $413310-4786$

e-mail: dalcioreis@terra.com.br

Nome completo: HÉLIO GOMES DE CARVALHO

Filiação institucional: Professor do programa de pós-graduação em Tecnologia - UTFPR

Departamento: PPGTE

Função ou cargo ocupado: Professor.

Endereço completo para correspondência (bairro, cidade, estado, país e CEP): Centro, Av. Sete de Setembro, 3165, Curitiba, PR, Brasil, 80.230-901 
Telefones para contato: 41 3310-4786

e-mail: heliogcarvalho@terra.com.br 